\title{
Os currículos brasileiros e suas políticas sob as perspectivas socioculturais da Educação Matemática: das prescrições aos currículos pensadospraticados
}

The brasilian curriculums and their policies under the sociocultural perspectives of mathematics educacion: from the prescriptions to the thoughtpracticed curriculums

Los currículos brasileños y sus políticas bajo las perspectivas socioculturales de la educación matemática: de las prescripciones a los currículos pensadospracticados

\section{JÚLIO CÉSAR AUGUSTO DO VALLE ${ }^{1}$}

${ }^{1}$ Universidade de São Paulo

\begin{abstract}
RESUMO: O propósito deste texto consiste em sistematizar os principais tópicos alcançados pelas práticas-pesquisas no contexto do Grupo de Estudos e Pesquisa em Etnomatemática (GEPEm) da Faculdade de Educação da Universidade de São Paulo, que buscam discutir, sintetizar e endereçar as principais contribuições e indagações formuladas no âmbito das perspectivas socioculturais da Educação Matemática para/ sobre os curriculos de matemática e suas políticas. Para isso, consideram-se as prescrições curriculares brasileiras, desde a primeira metade do século XX até a presente década, para discuti-los à luz. de autores e epistemologias que reconbecem a necessidade de pensar os curriculos sob as perspectivas que consideram o conhecimento matemático escolarizado em função das relações e das práticas socioculturais que permeiam sua formulação como saber.
\end{abstract}

POLÍTICA CURRICULAR. ETNOMATEMÁTICA. CURRÍCULO DE MATEMÁTICA. DESINVISIBILIZAR.

\begin{abstract}
$\boldsymbol{A B S T R A C T : ~ T h e ~ p u r p o s e ~ o f ~ t h i s ~ t e x t ~ i s ~ t o ~ s y s t e m a t i z e ~ t h e ~ m a i n ~ t o p i c s ~ r e a c h e d ~ b y ~ r e s e a r c h ~ p r a c t i c e s ~ i n ~}$ the context of the Group of Studies and Research in Ethnomathematics (GEPEm) of the Faculty of Education of the University of São Paulo, which seek to discuss, synthesize and address the main contributions and inquiries made within the scope of the socio-cultural perspectives of Mathematics Education for / about mathematics curricula and their policies. To this end, Braqilian curricular prescriptions are considered, from the first half of the twentieth century to the present decade, to discuss them in the light of authors and epistemologies that recognize the need to think curricula under the perspectives that consider school mathematical knowledge due to the sociocultural relations and practices that involve the formulation of this knowledge.CURRICULUM POLICY. ETHNOMATHEMATICS. MATHEMATICS EDUCATION. MATH CURRICULUM. DISINVISIBILIZAR.
\end{abstract}

Os autores cedem à Revista Internacional Educon os direitos de primeira publicação do presente artigo. Aplicam-se os termos de uma licença Creative Commons Atribuição 4.0 Internacional (CC BY 4.0), que permite o uso irrestrito, a distribuição e a reprodução em qualquer meio desde que a publicaşão original seja corretamente citada. 
RESUMO: El objetivo de este texto es sistematizar los principales temas alcanzados por las prácticas de investigación en el contexto del Grupo de Estudios e Investigación en Etnomatemática (GEPEm) de la Facultad de Educación de la Universidad de São Paulo, que buscan debatir, sintetizar y abordar las principales contribuciones. y consultas realizadas dentro del alcance de las perspectivas socioculturales de la Educación Matemática para / sobre los planes de estudio de las matemáticas y sus políticas. Con este fin, se considera que las recetas curriculares brasileñas, desde la primera mitad del siglo XX hasta la década actual, las discuten a la luz de autores y epistemologías que reconocen la necesidad de pensar los planes de estudio desde las perspectivas que consideran el conocimiento matemático escolar. debido a las relaciones y prácticas socioculturales que implican la formulación de este conocimiento.

\section{POLÍTICA CURRICULAR. ETNOMATEMÁTICAS. EDUCACIÓN MATEMÁTICA. CURRICULUM DE MATEMÁTICAS. DESINVISIBILIZAR.}

\section{Introdução}

Conforme elucidou Wagner Palanch (2016) em sua tese de doutoramento, há em curso, no Brasil, um movimento de contínua, ainda que não regular, expansão das pesquisas que tomam como objeto de investigação os currículos de matemática. Desde o enfoque nas prescrições curriculares, os currículos oficiais, até o enfoque nos currículos praticados/reais, tais investigações têm assumido distintas perspectivas teórico-metodológicas e se multiplicam, ainda desigualmente, em território nacional. Esse fato, em particular, chamou a atenção de pesquisadores que constituem o Grupo de Estudos e Pesquisa em Etnomatemática (GEPEm) da Faculdade de Educação da Universidade de São Paulo, interessados em contribuir com a reflexão curricular a partir das perspectivas socioculturais da Educação Matemática, dentre as quais destacamos a própria Etnomatemática.

Posto isso, retornamos à reflexão de Palanch que, após mapear as pesquisas sobre currículos de matemática nas três décadas mais recentes da história brasileira, endereça-nos algumas questões relevantes sobre o campo, capazes de sintetizar preocupações e tensões sobre as quais outras pesquisas podem se debruçar a partir do caminho por ele percorrido. Segundo o autor, tais questões emergiram no decorrer de sua investigação:

- Como os formadores podem contribuir para que professores se apropriem de documentos curriculares e das teorias e concepções de ensino e de aprendizagem subjacentes? (...)

- No que o conhecimento sobre currículos contribui para o desenvolvimento profissional docente? (...)

- Que concepções de currículo tem a comunidade de educadores matemáticos?

- Como promover/potencializar a autoria docente no processo de elaboração e desenvolvimento curricular? (Palanch, 2016, pp. 152-153)

Assim, como uma tentativa de contribuir com essas questões, propomo-nos ao compartilhamento de resultados de investigações, cujo propósito consiste em sintetizar as principais contribuições e indagações formuladas no âmbito das perspectivas socioculturais da Educação Matemática para/sobre os currículos de matemática. Para isso, consideram-se as prescrições curriculares brasileiras, desde a primeira metade do século XX até a presente década, para discutir em que medida incorporaram ou não os referenciais, autores e epistemologias que reconhecem a necessidade de pensar os currículos sob as perspectivas que consideram o conhecimento matemático escolarizado em relação às relações e práticas socioculturais que o envolvem, desde a própria formulação desses saberes até seu ensino-aprendizagem escolar. Este texto se encerra, então, com a proposta de que possamos promover, nas regiões de inquérito sobre os currículos de matemática, deslocamentos das prescrições curriculares aos currículos praticados. 
Revista Internacional Educon, Volume I, n. 1, e20011012, set./dez. 2020

ISSN: 2675-6722 | DOI: https:// doi.org/ 10.47764/ e20011010

Para fundamentar teoricamente esta proposta, recorremos à produção científica tanto no campo dos currículos como também propriamente à produção oriunda das investigações sobre currículos de matemática.

Em relação aos primeiros, valemo-nos das contribuições, em especial, da professora-pesquisadora Inês Barbosa de Oliveira (2012), da Universidade Estadual do Rio de Janeiro (UERJ), que nos informa sobre modos de compreender os currículos praticados a partir da invisibilidade que lhes é atribuída/imposta pelos processos de prescrição curricular. Seus conceitos permeiam a tessitura do trabalho porque subjazem à leitura que faremos do modo como as perspectivas socioculturais da Educação Matemática podem conceber o campo do currículo como território de disputa em torno das pautas que lhes são caras.

Em relação à produção oriunda das investigações sobre currículos de matemática, valemo-nos das perspectivas expressas por Pires (2008), Pires e Silva (2011), Oliveira (2002), Palanch (2016) e Bigode (2019), que nos informam sobre o estado dos currículos de matemática desde o contexto das reformas educacionais brasileiras da primeira metade do século passado até o contexto da Base Nacional Comum Curricular (BNCC, Brasil, 2017). Em maior medida, nos apoiamos nos referenciais de Valle \& Santos (2018) e Valle \& Conrado (2019), que têm se dedicado a - a partir, inclusive, de Oliveira (2012) e outras produções convergentes - problematizar a ideia de que currículo seja algo do âmbito da "implementação", como se fosse possível e desejável ver instaurada uma certa prática prescritiva, qualquer que seja sua natureza. Os autores nos provocam, assim, à busca de práticas-políticas curriculares (de matemática) capazes de acolher, criticamente, o tempo e a ação dos atores locais que compõem as escolas, os praticantes do currículo.

Argumentaremos sobre esse movimento, de inversão do vetor da política curricular que propõem os autores, ser desejável no contexto das perspectivas socioculturais da Educação Matemática.

\section{Prescrição e centralização: os currículos de matemática no Brasil}

Em nossa pesquisa, consideramos os documentos oficiais, em sua sequência histórica, com o propósito de compreender em que medida consideraram as contribuições oriundas das perspectivas socioculturais da Educação Matemática, que se consolidaram na segunda metade do século XX, nominalmente por meio da Etnomatemática, ainda que registremos desenvolvimentos substantivos da Educação Matemática Crítica (Valero \& Skovsmose, 2012) ou a Sociologia da Matemática (Bauchspies \& Restivo, 2001), capazes de acolher perspectivas críticas, antropológicas, não-monolíticas e nãoortodoxas em relação ao que se considera como conhecimento matemático e também sua formulação. Assumimos, nesse contexto, a perspectiva de Pires e Silva (2011, p. 58), quando afirmam que:

As análises das Reformas Francisco Campos (1931) e Gustavo Capanema (1942) evidenciam, por exemplo, que as inovações curriculares na área de Matemática, propostas pelo professor Euclides Roxo, no âmbito da Reforma Francisco Campos, foram atacadas na reforma seguinte com argumentos pouco convincentes. Exemplo disso era a unificação dos campos matemáticos — Álgebra, Aritmética e Geometria — numa única disciplina, a Matemática, de modo a abordálos de forma inter-relacionada. Também na Reforma Campos, houve uma orientação de que o ensino da geometria dedutiva deveria ser antecedido de uma abordagem prática da geometria. Mas essas ideias acabaram por se fortalecer bem posteriormente. Se na Reforma Francisco Campos, a concepção de currículo foi ampliada para além da mera listagem de conteúdos a serem ensinados, incluindo uma discussão de orientações didáticas, na reforma seguinte, essa importante conquista não se consolidou.

Logo, não há até esse momento qualquer formulação mais crítica do ponto de vista tanto do currículo como também do conhecimento matemático. Isso se justifica pelo fato de que muitas propostas críticas somente se consolidariam no ambiente acadêmico algumas décadas após tais reformas ocorrerem. Nos currículos prescritos ensejados no âmbito das reformas supracitadas, a Matemática emerge, pela

Os autores cedem à Revista Internacional Educon os direitos de primeira publicação do presente artigo. Aplicam-se os termos de uma licença Creative Commons Atribuição 4.0 Internacional (CC BY 4.0), que permite o uso irrestrito, a distribuição e a reprodução em qualquer meio desde que a publicação original seja corretamente citada. 
primeira vez na história brasileira, como a unificação de campos por meio dos quais a compreendemos hoje. Ademais, cumpre-nos destacar que, além da listagem dos conteúdos a serem ensinados, a Reforma Francisco Campos inclui, também de forma inédita nas prescrições curriculares, certa discussão de orientações didáticas sobre o trabalho pedagógico com a Matemática, o que não permanece na reforma seguinte.

Depois de algumas décadas, no período que vai de 1960 a 1980, coincidente com a ditadura militar brasileira, consolida-se o Movimento da Matemática Moderna. Sobre esse movimento, importa-nos considerar que:

Os currículos oficiais foram progressivamente incorporando o ideário do Movimento, curiosamente influenciados por coleções de livros didáticos que saíram à frente dos órgãos governamentais, introduzindo temas relativos à Teoria dos Conjuntos, enfatizando o uso da linguagem simbólica. Pelo fato de ter sido veiculado pelos livros didáticos, esse ideário chegou rapidamente às escolas e teve grande influência, especialmente na seleção de conteúdos a serem ensinados. Com as críticas ao Movimento Matemática Moderna e também com a demanda de novas orientações curriculares, mais identificadas com o contexto educacional brasileiro, novas ideias começaram a ser incorporadas aos currículos de modo geral e, em particular, aos de Matemática. (Pires \& Silva, 2011, p. 58)

Também não é de se esperar que, neste momento, haja qualquer problematização da política curricular ou da natureza do conhecimento matemático, compreendendo seu caráter cultural, humano, "frágil e falível" (Ernest, 1991). Porém, com a reabertura democrática isso tende a mudar, tanto porque tais problematizações começaram a se avolumar no campo dos currículos e na Educação Matemática, como também porque a democracia é um ambiente político mais fértil para acolher tais proposições.

Experiências relevantes no contexto das políticas curriculares em alguns estados e municípios brasileiros - de que São Paulo é exemplo destacado por ter Paulo Freire como Secretário Municipal de Educação (Valle \& Santos, 2018; Oliveira, 2002), conforme abordaremos adiante também neste texto florescem desafiando a ideia de que a imposição de uma política curricular centralizadora e prescritiva seja o único caminho para estruturar as políticas curriculares. Essas experiências nos conduzirão a um processo de reflexão e de disputa curriculares que se consolidam por meio, inclusive, da legislação (tanto no próprio texto constitucional como no texto da Lei de Diretrizes e Bases da Educação Nacional).

Como decorrência de parte dessas reflexões, temos os Parâmetros Curriculares Nacionais (PCN, Brasil, 1997), que avançam, em alguma medida, em relação ao estado da política curricular nacional anterior. Isso porque:

Destacam a importância de superar a organização linear dos conteúdos e a necessidade de explicitar as conexões entre eles, inspirando-se na metáfora de construção do conhecimento como "rede de significados".

- Incorporam, já no ensino fundamental, o estudo da probabilidade e da estatística e evidenciam a importância da geometria e das medidas para desenvolver as capacidades cognitivas fundamentais.

- Indicam a Resolução de Problemas como ponto de partida da atividade Matemática e discutem caminhos para "fazer Matemática" na sala de aula, destacando a importância da História da Matemática, da Etnomatemática, da Modelagem e das Tecnologias da Informação e da Comunicação. (Pires \& Silva, 2011, p. 63, grifos nossos)

Com efeito, textualmente, os PCN (1997, p. 21) partem do reconhecimento de que existe "pouca vinculação da Matemática às suas aplicações práticas” para pensar alternativas contextualizadas e relacionadas às práticas culturais nas quais se constitui-utiliza-mobiliza conhecimentos matemáticos. Nesse ponto, o documento menciona que:

Dentre os trabalhos que ganharam expressão nesta última década, destaca-se o Programa Etnomatemática, com suas propostas alternativas para a ação pedagógica. Tal programa contrapõe-se às orientações que desconsideram qualquer relacionamento mais íntimo da Matemática com aspectos socioculturais e políticos - o que a mantém intocável por fatores outros a não ser sua própria dinâmica interna. Do ponto de vista educacional, procura entender 


\section{Revista Internacional Educon, Volume I, n. 1, e20011012, set./dez. 2020 ISSN: 2675-6722 | DOI: https:// doi.org/10.47764/e20011010}

os processos de pensamento, os modos de explicar, de entender e de atuar na realidade, dentro do contexto cultural do próprio indivíduo. A Etnomatemática procura partir da realidade e chegar à ação pedagógica de maneira natural, mediante um enfoque cognitivo com forte fundamentação cultural. (Brasil, 1997, p. 21, grifos nossos)

Em que pese o fato de não haver exatamente um consenso sobre a concepção de Etnomatemática, de que partilhamos a noção de D'Ambrosio (2020), reconhecê-la como uma contribuição relevante para situar conhecimentos matemáticos, junto à História da Matemática, à Modelagem Matemática e às Tecnologias da Informação e da Comunicação, no âmbito das práticas socioculturais representa um movimento interessante para estimular práticas inspiradas em suas premissas, ao invés de tomá-la como prescrição metodológica. No contexto da Pluralidade Cultural, tomada como um dos eixos do documento, afirma-se que: "A construção e a utilização do conhecimento matemático não são feitas apenas por matemáticos, cientistas ou engenheiros, mas, de formas diferenciadas, por todos os grupos socioculturais" (BRASIL, 1997, p. 27). Compreender de que formas é possível considerar essa afirmação no trabalho pedagógico passa a ser um dos objetivos do ensino de matemática. "Nesse trabalho", continua o documento, "a História da Matemática, bem como os estudos da Etnomatemática, são importantes para explicitar a dinâmica da produção desse conhecimento, histórica e socialmente" (Brasil, 1997, p.28).

Com o aprofundamento e o alargamento das disputas em torno dos currículos e da política curricular, novas conquistas são celebradas quando aprovadas as Leis Federais 10.639, em 2003, e 11.645, em 2008, dispondo sobre a necessidade de considerar a História e Cultura Afro-brasileira e Africana,num primeiro momento, e Indígena, posteriormente. Sobre isso, a pesquisadora Nilma Lino Gomes afirma que:

Dada a sua importância na constituição da nossa sociedade, esses saberes deveriam fazer parte da educação escolar, dos projetos educativos não escolares e do campo do conhecimento de maneira geral, sobretudo após a alteração da Lei 9.394/96 (Lei de Diretrizes e Bases) pela Lei 10.639/03, que torna obrigatório o ensino de História e Cultura Afro-brasileira e Africana nos currículos das escolas de ensino Fundamental e Médio, públicas e particulares. Essa lei foi regulamentada pela Resolução CNE/CP 01/04 e pelo parecer CNE/CP 03/04, que instituem as Diretrizes Curriculares Nacionais para a Educação das Relações Étnico-raciais e para o Ensino de História e Cultura Afro-brasileira e Africana. Os deveres da União, estados, municípios, Distrito Federal, universidades, conselhos e demais setores ligados à educação para com a implementação dessa legislação foram registrados em 2009 no Plano Nacional de Implementação das Diretrizes Curriculares Nacionais. Os saberes expressos nesses documentos ainda não são devidamente considerados enquanto tais pelo campo do conhecimento e pela teoria educacional. Trata-se de uma disputa, principalmente, no campo dos currículos. (Gomes, 2017, p. 68)

No contexto das Diretrizes Curriculares Nacionais para a Educação das Relações Étnico-raciais e para o Ensino de História e Cultura Afro-brasileira e Africana (Brasil, 2004), faz-se novamente menção à Etnomatemática e à necessidade de compreender a natureza cultural do conhecimento não apenas matemático, mas, mais amplamente, do conhecimento "acumulado pela humanidade", de que têm sido historicamente negligenciados diferentes modos de compreender/representar e intervir na realidade, em especial das comunidades tradicionais, povos negros e indígenas.

Com efeito, diferentes pesquisas (Costa \& Silva, 2010; 2016) realizadas por membros do GEPEm, vêm discutindo, desde 2001 pelo menos, o modo como se relacionam as culturas negras, africanas e afrobrasileiras, e indígenas com a matemática escolar, sob a perspectiva da Etnomatemática. Os resultados dessas pesquisas nos endereçam uma relevante problemática, centrada no fato de que, na medida em que as prescrições curriculares ignoram a ausência de povos, grupos e comunidades distintos e seus saberesfazeres na construção do que chamam de "conhecimentos acumulados pela humanidade", multiplicamse nas escolas

(...) relatos de crianças e jovens negros tolhidos no seu desenvolvimento e autoestima por serem feridos na sua dignidade, na comparação de valores e saberes históricos, estéticos, familiares e

Os autores cedem à Revista Internacional Educon os direitos de primeira publicação do presente artigo. Aplicam-se os termos de uma licença Creative Commons Atribuição 4.0 Internacional (CC BY 4.0), que permite o uso irrestrito, a distribuição e a reprodução em qualquer meio desde que a publicação original seja corretamente citada. 
sociais que tomam como referência a cultura dominante imposta a eles pelos currículos. (...) Por sua vez, as culturas indígenas se fazem presentes no currículo de escolas não indígenas como um produto folclórico, como algo do passado e que não diz respeito à atualidade brasileira. (Costa \& Silva, 2010, p. 248)

As Diretrizes Curriculares Nacionais para a Educação das Relações Étnico-raciais e para o Ensino de História e Cultura Afro-brasileira e Africana acolheram, portanto, a necessidade de se problematizar o status do conhecimento matemático, produto cultural de inúmeras disputas sociais em torno dos sentidos e dos significados de compreender e representar o mundo. Esses modos de compreender, representar, interagir e intervir no/com o mundo compõem sistemas complexos que, sob a perspectiva da Etnomatemática que adotamos, "incluem, invariavelmente, em todos os tempos e lugares no mundo, estratégias de observação, de comparação, de classificação, de avaliação, de quantificação, de mensuração, representação, inferência e comunicação”, conforme elucida D’Ambrosio (2020, p. 7, tradução nossa).

Não faz sentido, portanto, que sejam considerados como "conhecimentos acumulados pela humanidade" estratégias de observação, de comparação, de classificação, de avaliação, de quantificação, de mensuração, representação, inferência e comunicação" não "universais", mas universalizados por meio das inúmeras disputas, muitas delas coincidentes com processos violentos de escravização e colonização, responsáveis pelo que Boaventura Sousa Santos (2007) tem chamado de epistemicídio. Disputas com indiscutíveis implicações para o que Michael Apple (2011) vai compreender como "política do conhecimento oficial", representada expressamente - desde os pressupostos que assume até os interesses que a ensejam - a política de estabelecimento de uma Base Nacional Comum Curricular, como discutiremos adiante. No contexto das DCN, mais consistentes e ideologicamente melhor posicionadas do que a Base que temos hoje, porém, discutia-se o fato de que:

Para obter êxito, a escola e seus professores não podem improvisar. Têm que desfazer mentalidade racista e discriminadora secular, superando o etnocentrismo europeu, reestruturando relações étnico-raciais e sociais, desalienando processos pedagógicos. Isto não pode ficar reduzido a palavras e a raciocínios desvinculados da experiência de ser inferiorizados vivida pelos negros (...) Temos, pois, pedagogias de combate ao racismo e a discriminações por criar. E claro que há experiências de professores e de algumas escolas, ainda isoladas, que muito vão ajudar. (Brasil, 2004, p. 15)

Recentemente,a SBEM coassinou, enquanto entidade educacional representante dos/as educadores/as matemáticos/as brasileiros/as, ofícios elaborados pela Associação Nacional de Pósgraduação e Pesquisa em Educação (ANPEd) e pela Associação Brasileira de Currículo (ABdC), interpelando Ministros da Educação, seus secretários e diretores relacionados à elaboração da Base, Deputados da Comissão de Educação e o próprio Conselho Nacional de Educação (CNE) sobre inconsistências, inflexões inexplicadas, além do caráter antidemocrático que seu processo de formulação assumiu (ANPEd \& ABdC, 2015). Esses ofícios nunca foram sequer respondidos. Não surpreende, portanto, que a redação contida no excerto anterior esboce preocupações muito mais autênticas da comunidade educacional brasileira do que o mero alcance de competências e habilidades que a Base proporia - inclusive por terem seus formuladores, durante o processo, negligenciado as contribuições das entidades educacionais que, a exemplo da ANPEd, ABdC e SBEM dentre tantas outras, manifestariam-se criticamente.

Avançando na discussão de como a escola pode contribuir para o enfrentamento do racismo e da discriminação, lemos nas DCN que:

Inclusão, respeitada a autonomia dos estabelecimentos do Ensino Superior, nos conteúdos de disciplinas e em atividades curriculares dos cursos que ministra, de Educação das Relações Étnico-Raciais, de conhecimentos de matriz africana e/ou que dizem respeito à população negra. Por exemplo: em Medicina, entre outras questões, estudo da anemia falciforme, da problemática da pressão alta; em Matemática, contribuições de raiz africana, identificadas e descritas pela Etno-Matemática; em Filosofia, estudo da filosofia tradicional africana e de contribuições de filósofos africanos e afrodescendentes da atualidade. (Brasil, 2004, p. 24, grifos nossos) 
Revista Internacional Educon, Volume I, n. 1, e20011012, set./dez. 2020 ISSN: 2675-6722 | DOI: https:// doi.org/ 10.47764/ e20011010

Nesse momento, a política curricular, ainda que "oficial" e diretiva, incorpora diferentes tendências e tradições pedagógicas que confirmam seu caráter híbrido (Brasil, 2010, p. 44) e que evidentemente permitem uma menção à existência de subsídios, no contexto da Educação oriundos das pesquisas-práticas em Etnomatemática - de que D’Ambrosio (2010; 2020) têm sido, desde sua idealização, um de nossos principais referenciais - capazes de contribuir com a prática dos professores e das professoras de matemática interessados/as em conhecer modos de pensar/fazer sobre o racismo em sua sala de aula, em sua escola (Costa \& Silva, 2010; 2016).

Regredimos, como veremos, com a promulgação da BNCC, já mencionada, cujo propósito consiste em "nortear os currículos dos sistemas e redes de ensino das Unidades Federativas, como também as propostas pedagógicas de todas as escolas públicas e privadas de Educação Infantil, Ensino Fundamental e Ensino Médio, em todo o Brasil” (Brasil, 2017). Além da crítica sobre o fato de documento desconsiderar todas as pesquisas-políticas-práticas orientadas no sentido de compreender o conhecimento matemático como prática sociocultural específica, não há sequer menção à Etnomatemática, que desaparece, por enquanto, da política curricular nacional, mais centralizadora e prescritiva do que qualquer outro documento já produzido antes em nosso país. Não cabe a nossa já frágil democracia - que se pretende, inclusive democracia epistemológica - tolerar a possibilidade de que um grupo de poucos se autoproclamem capazes de prescrever o que diferentes escolas terão de fazer nos mais diferentes contextos, ao mesmo tempo, desconsiderando a contribuição das pesquisas em Modelagem Matemática, História da Matemática, Sociologia da Matemática, Educação Matemática Crítica e, especialmente em nosso caso, em Etnomatemática.

Primeiro, porque essa área tem sido identificada como capaz de subsidiar respostas, práticaspolíticas, de enfrentamento ao racismo, como a política curricular nacional vinha afirmando nos PCN, de modo mais implícito, e nas DCN, de maneira explícita. Sua exclusão, bastante simbólica, de um documento construído a partir de um processo altamente antidemocrático (Dourado \& Aguiar, 2018), pode ser compreendida como um posicionamento da Etnomatemática - como nome capaz de agrupar diferentes pesquisadores/as e professores/as mobilizando diferentes pesquisas-práticas diametralmente oposto à política nacional curricular vigente, devido expressamente ao seu caráter antidemocrático, prescritivo e centralizador:

A discussão sobre como a Matemática é apresentada na Base Nacional Comum Curricular (BNCC) proposta-imposta pelo Ministério da Educação (MEC), pode ser feita de múltiplas perspectivas, da visão epistemológica sobre a natureza do pensamento matemático à concepção didática que veicula. Ainda que seus defensores tentem aparentar neutralidade, sustentando uma suposta assepsia ao bater na tecla de que "a matemática é imune a ideologias" ou de que "base não é currículo", o documento não consegue esconder sua orientação ideológica expressa numa visão que reduz a matemática a uma coleção estanque de itens que não passam de descritores de avaliação, agora rebatizados de "habilidades". (Bigode, 2019, p. 123)

Observa-se, nesse sentido, que a insatisfação da comunidade acadêmica vinculada à Educação Matemática com a Base e o que ela representa, em termos de política educacional, fundamenta-se na crítica feita sob as perspectivas socioculturais, além, evidentemente, das críticas oriundas da psicologia e história da matemática:

Como apresenta-se a proposta, onde os números vão aparecendo magicamente dissociados da construção de estruturas, há equívoco tanto na capacidade cognitiva de nossas crianças como no trato metodológico para expansão e desenvolvimento do sistema numérico, fazendo com que no primeiro ano o trato se limita ao 30 e no segundo tendo como referência o 100, o que revela profundo equívoco, quanto aos processos de alfabetização matemática. (Muniz apud Bigode, 2019, p. 131)

Também há, no posicionamento de Cristiano Alberto Muniz, ex-presidente da SBEM, trechos que nos remetem às perspectivas socioculturais da Educação Matemática, como compartilhamos a seguir:

(...) Faltam as perspectivas históricas e da etnomatemática, que não são contempladas na BNC. Assim, valores sociais, culturais e afetivos do aprender matemática não estão explicitados na aprendizagem escolar da matemática proposta pela BNC, não trazendo de forma explícita as

Os autores cedem à Revista Internacional Educon os direitos de primeira publicação do presente artigo. Aplicam-se os termos de uma licença Creative Commons Atribuição 4.0 Internacional (CC BY 4.0), que permite o uso irrestrito, a distribuição e a reprodução em qualquer meio desde que a publicação original seja corretamente citada. 
tendências da Educação Matemática, tais como o enfoque histórico, cultural, comunicacional, lúdico, assim como as novas tecnologias que, quando presentes são marginais e alegóricas. Em síntese, parece haver um silenciamento na proposta do que é extraescolar, dos aspectos da história da matemática, dos temas transversais. (Muniz apud Bigode, 2019, p. 132)

Às críticas de Muniz, acrescentadas, evidentemente, as críticas feitas também por Bigode (2019), que reuniu críticas de educadores/as matemáticos/as sérios formuladas no decorrer do processo de formulação da Base. Além de registrá-las, Bigode (2019, p. 134) acresce suas próprias como, por exemplo, "Introduz-se o conceito de múltiplo no $6^{\circ}$ ano, mas a resolução de problemas sobre múltiplos aparece somente no $7^{\circ}$ ano. Como se pode aprender um conceito apartado dos problemas que o geram?”.

Todo o cenário de críticas formuladas à BNCC tanto no contexto das entidades educacionais como ANPEd e ABdC (2015), muitas delas subscritas pela SBEM, como também no contexto das pesquisas-práticas de diferentes autores/as que lhe endereçaram críticas, fundamenta a perspectiva expressa do ex-presidente SBEM Cristiano Muniz que o fará afirmar que:

No que diz respeito às aprendizagens matemáticas, com base na perspectiva teóricoepistemológica, quanto metodológica da Educação Matemática, revela, em muitos aspectos, um certo retrocesso em relação aos avanços conquistados nos últimos documentos e políticas do MEC, em especial dos PCN, GESTAR, Direitos de Aprendizagem e Desenvolvimento, e mais, recentemente, do PNAIC de matemática. Além disso, conhecimentos fundamentais consolidados por meio da pesquisa científica no campo da Educação Matemática não são contemplados na proposta. Ao contrário, vemos alguns retrocessos inexplicáveis e insustentáveis. (Muniz apud Bigode, 2019, p. 129)

Posto isso, o cenário que nos foi proposto-imposto, para utilizar a expressão de Bigode (2019), com a Base Nacional Comum Curricular, pode ser incluído na afirmação feita por Pires e Silva (2011, p. 58) sobre a história das políticas curriculares nacionais e seus reflexos para o currículo de matemática:

O estudo do desenvolvimento de currículos no Brasil mostra que as decisões curriculares foram historicamente marcadas por ações governamentais e não oriundas de movimentos nascidos nas escolas, protagonizadas por professores ou pela sociedade civil. Uma das marcas das políticas públicas brasileiras, no que se refere a questões curriculares, é a falta de ações de implementação curricular, como se novas ideias se transformassem em prática, num passe de mágica. Além da ausência de ações de implementação, outra marca é a falta de acompanhamento/avaliação das inovações propostas, o que não permite fazer uma avaliação adequada, contabilizando acertos e erros.

Discordamos expressamente da ideia de que seja possível e desejável “implementar um currículo”ideia negadora da existência e da legitimidade dos currículos pensadospraticados de que trataremos adiante - inclusive por compreendermos que a ideia da "implementação curricular" tem perpassado a lógica de diferentes práticas-políticas-pesquisas até chegar à Base Nacional Comum Curricular, que representa seu auge nas políticas curriculares nacionais. A prescrição e a centralização têm marcado, juntas, a história da política curricular brasileira, à despeito das mencionadas exceções, inclusive nos currículos de matemática. Porém, também sabemos que outras experiências foram/são/serão possíveis, conforme o argumento de Valle (2020) de que Freire, ao inscrever outra possibilidade de pensarfazer a escola pública democrática em sua política curricular, demonstra-nos sua viabilidade ontológica inscrita na história da educação brasileira, possível. Para que compreendamos melhor essa afirmação, dedicamo-nos adiante à discussão, em zoom, para utilizar uma expressão de Lynlia Sachs (2018), sobre a experiência da política curricular promovida sob a gestão de Paulo Freire, na Secretaria Municipal de Educação de São Paulo.

\section{A Matemática no Movimento de Reorientação Curricular de Paulo Freire}


Revista Internacional Educon, Volume I, n. 1, e20011012, set./dez. 2020 ISSN: 2675-6722 | DOI: https:// doi.org/10.47764/e20011010

Analisando o movimento de planejamento educativo e curricular nas políticas mobilizadas quando o educador Paulo Freire atuou como Secretário Municipal de Educação de São Paulo, de 1989 a 1992, as pesquisadoras do campo do currículo Alice Lopes e Elizabeth Macedo (2011, pp. 64-65) elucidam que:

O planejamento se inicia com a identificação das contradições básicas a partir de cuja análise emerge um tema gerador geral. Essa identificação se dá pela análise da realidade social em que se insere a escola, mas, diferentemente do que ocorre na racionalidade tyleriana, o que está em destaque é a forma como os sujeitos vivenciam essa realidade. Assim, professores e alunos (e comunidade) são participantes ativos no processo de identificação do tema gerador geral. A segunda etapa do planejamento é a seleção de temas geradores (ou palavras geradoras, no caso da alfabetização) que comporão o currículo e sua codificação e decodificação. Para a seleção desses temas, procede-se a uma análise sistemática, para além de limites disciplinares, de modo a reduzi-los àqueles com maior potencial educativo, ou seja, a partir dos quais a realidade vivencial possa ser problematizada. Cada tema é codificado por urna situação que o representa e o exemplifica (urna fotografia ou um texto, por exemplo), sendo fundamental que essa situação seja existencialmente significativa para os sujeitos. A última etapa do planejamento é a elaboração de material para, utilizando a metodologia dialógica, garantir a problematização dos temas, devolvendo, de forma sistematizada aos alunos, os elementos que eles entregaram de forma desestruturada por ocasião da investigação do universo temático.

Os princípios de participação, descentralização e autonomia que orientaram as políticas gestadas no governo de Luiza Erundina (Partido dos Trabalhadores), em que Freire atuou como Secretário Municipal de Educação, contribuíram para que a política curricular apresentada à rede municipal incorporasse, democraticamente, a experiência de professoras e de professores no trabalho pedagógico, realizado em parceria com as universidades. O Movimento construído por Freire e sua equipe se distinguia das tradicionais prescrição curricular, pois pautava-se, antes disso, nessas experiências pedagógicas já em curso na rede municipal para construir coletiva e participativamente os documentos curriculares que, longe de prescrever, compartilhavam práticas emancipatórias realizadas em meio às parcerias estabelecidas (Valle \& Santos, 2018).

No Documento de Visão de Área de Matemática, construído a muitas mãos no decorrer do movimento freireano, lia-se que:

No dia-a-dia da sala de aula, em muitas escolas atuais, nem todas da rede privada, a Matemática já abandonou as sequências de regras, a ênfase na memorização, o adestramento intensivo dos algoritmos. Abandonou também as preocupações com conjuntos e estruturas da Matemática Moderna. Converteu-se em uma disciplina mais integrada à realidade do educando, na qual este é solicitado a criar e participar da construção do conhecimento. No entanto, as novas concepções ainda só alcançam uma parcela pequena das escolas brasileiras. Paralelamente desenvolvem-se hoje pesquisas sobre educação matemática com uma intencionalidade jamais vista em qualquer outro momento histórico. (PMSP/SME, 1992, p. 9)

A contribuição de outras áreas de pesquisa e de prática da educação matemática são sinalizadas pelos autores como renovadas possibilidades teóricas de repensar o ensino e a aprendizagem da matemática, a exemplo daquelas que, conforme diz o documento, têm como foco aspectos sociais relacionados à educação - de onde também têm derivado propostas pedagógicas, conforme reconhecem. Nos termos do documento:

Destas propostas destacamos: a etnomatemática, que busca valorizar o conteúdo matemático de diferentes grupos sociais e os conceitos informais construídos pelo educando em sua vida extraescolar; a utilização da História da Matemática, que tem servido como instrumento para motivar o aprendizado e propiciar aquisição de conceitos, defrontando o aluno eventualmente com obstáculos semelhantes pelos criadores desses conceitos. O movimento atual da educação matemática permite vislumbrar um futuro no qual essa disciplina não mais parecerá destituída de sentido ou assustadora, como o foi para a maioria dos estudantes nos últimos dois ou três séculos. (PMSP/SME/1992, pp. 9-10, grifos nossos)

Os autores cedem à Revista Internacional Educon os direitos de primeira publicação do presente artigo. Aplicam-se os termos de uma licença Creative Commons Atribuição 4.0 Internacional (CC BY 4.0), que permite o uso irrestrito, a distribuição e a reprodução em qualquer meio desde que a publicação original seja corretamente citada. 
Outra mudança esperada por Freire, pessoalmente, na prática dos professores de matemática consistia no enfrentamento do lugar relegado à matemática que, nas palavras do educador, era ensinada como "coisa para deuses ou gênios" - conforme sua geração de brasileiros, especialmente no nordeste, aprendeu. Quando não deuses, "gênios, porque se fazia uma concessão ao sujeito genial, que podia fazer matemática sem ser deus", ironizava Freire (apud D’Ambrosio \& Domite, 1997, p. 8). Preocupava-se, nesse contexto, sobre "quantas inteligências críticas, quantas curiosidades, quantos indagadores, quanta capacidade abstrativa para poder ser concreta, perdemos".

Daí, também, a necessidade premente de que a universidade acolhesse o movimento, a fim de acompanhar os professores, as escolas, encaminhando suas principais tensões, respondendo às perguntas identificadas na vivência das dificuldades e dos desafios próprios do cotidiano, que estava se alterando.

Um caso exemplar dessa parceria entre as universidades, por meio de seus pesquisadores, e a Secretaria Municipal de Educação, concretizada no cotidiano das escolas, em cada reflexão desafiadora que impõe a seus praticantes é a produção da própria tese de doutorado de Domite, a que temos nos referido. Em seu trabalho, Domite busca compreender como se deu esse movimento de estímulo à problematização como caminho, como metodologia de ensino, não somente de matemática evidentemente, mas como eixo integrador de um currículo interdisciplinar. Acompanhando os professores nas escolas e produzindo sua pesquisa e tese em paralelo, Domite se dedicou a refletir justamente sobre os impasses e os caminhos experimentados pelos professores com quem trabalhou na construção desse currículo.

Consideramos as contribuições de Domite, em sua tese, como respostas instigantes aos desafios que temos identificado e às tensões experimentadas no momento, porque representam sínteses elucidativas do que a pesquisadora observou nas escolas nesse período. Nesse movimento, identificou quatro estratégias que foram utilizadas pelos professores de matemática da rede municipal, sobre as quais se dedica a refletir e discutir em seu trabalho. As quatro são: "flagrar situações no contexto escolar ou mais amplo", "convocar os alunos para a escola dos temas geradores", "partir de um assunto/tema previamente escolhido" e "partir de um modelo matemático conhecido" (Domite, 1993, p. 168). O potencial de seu trabalho reside justamente em ter conseguido descrever contextos reais de sala de aula, acompanhados pela pesquisadora, em que é possível identificar cada uma dessas estratégias em curso. Nessas situações, Domite discute teoricamente quais foram os potenciais e os limites encontrados por ela e pelos professores com quem trabalha durante a realização das atividades.

Sucintamente, descreveremos cada uma das estratégias identificadas nesse trabalho, em que é possível notar a convergência para o conteúdo proposto nos documentos orientadores. Na primeira delas, flagrar situações, "o professor deve estar atento para situações que começam a se revelar significativas para os alunos, ou seja, para perceber certas relações e particularidades" (p. 168). Domite sugere que os professores, ao utilizarem essa estratégia, identifiquem pontos de convergência entre temas que estão sendo debatidos pelos alunos e conteúdos matemáticos que possibilitem outras aproximações às mesmas temáticas, possibilitando aos alunos outras leituras. Aqui, o professor, como diz a autora, se insere num diálogo já iniciado pelos alunos para aproveitá-lo como disparador.

$\mathrm{Na}$ segunda estratégia, convocar os alunos para a escolha do tema, "o professor orienta a aprendizagem da Matemática a partir da necessidade de compreender uma situação da realidade social, problematizando-a" (Domite, 1993, p. 169). Aqui, o professor propõe intencionalmente a identificação de temas por parte dos alunos e planeja seu trabalho pedagógico para que os conteúdos matemáticos orbitem em torno do tema escolhido. Nas palavras de Domite, o professor utiliza essa estratégia "fazendo inicialmente uma análise crítica do ensino tradicional de Matemática e, em seguida, expondo uma situação de aprendizagem, geralmente por ele vivenciada com outro grupo de alunos, que se deu a partir de um tema gerador" (p. 169).

Partir de um tema previamente escolhido, a terceira estratégia, consistia em um caminho bastante utilizado, conforme sinaliza a autora, porque permite que o professor identifique, antes do contato com 
Revista Internacional Educon, Volume I, n. 1, e20011012, set./dez. 2020 ISSN: 2675-6722 | DOI: https:// doi.org/ 10.47764/ e20011010

os alunos, quais são possíveis e potenciais conexões entre o tema a ser proposto e os conteúdos matemáticos que serão desenvolvidos.

Cabe ao professor, a partir de um tema por ele escolhido, iniciar uma problematização que motive a ligação de conteúdos, que ele deseja introduzir, com situações reais que os alunos conhecem e vivenciam. Vale aqui ressaltar que essa proposta de encaminhamento de uma problematização não prioriza, como nas outras, partir de situações reais. Consideramos também, problematizar sobre situações fictícias, como uma simulação do real, um jogo. A arte do professor consiste então, em fazer nascer perguntas ligadas ao tema fixado (contexto escolhido, real ou não) e, de acordo com o interesse do grupo, procurar encaminhá-las enquanto problemas. (Domite, 1993, p. 169)

Vemos, no excerto apresentado, que, mesmo utilizando essa estratégia como caminho, o professor não se furta do debate com os alunos para identificar um conjunto de perguntas pertinentes ao contexto do tema escolhido para encaminhá-las. Significa dizer, por exemplo, que se a temática escolhida pelo professor é o saneamento básico ou as condições de habitação no bairro em que a escola está, são os alunos que encaminharão suas próprias perguntas sobre essas temáticas, com maior ou menor nível de profundidade ou de consciência crítica, de acordo com uma variedade de fatores, inclusive a faixa etária.

$\mathrm{Na}$ quarta e última estratégia identificada, partir de um modelo matemático, "a problematização, neste caso, constitui-se em um diálogo voltado para a análise de um problema análogo a um estudado, isto é, que utiliza este mesmo modelo matemático para sua solução” (p. 170). O professor, ao recorrer a essa estratégia, apresentava um modelo matemático conhecido que, de acordo com seu conhecimento, pode ser aplicável a outras situações-limite do cotidiano da comunidade em que a escola está inserida. Sua meta, portanto, passa a ser construir uma analogia entre o modelo apresentado e a capacidade de resolver um problema efetivamente experimentado pelos alunos e por suas famílias. Nas palavras da autora,

A partir do instrumental matemático que facilitou a conversão de um problema na sua linguagem matemática, o professor apresenta $e$ analisa problemas, dentro de outros contextos, que utilizam esse mesmo instrumental. Cabe ao professor inicialmente, encaminhar uma problematização com questões que argumentem sobre a busca de um problema semelhante do ponto de vista matemático, gerado em outro contexto. Uma vez localizado o problema, estender o diálogo para interpretar o modelo matemático estudado no primeiro problema, na linguagem do segundo. (Domite, 1993, p. 170)

Trata-se, também, de um caminho profícuo para pensarmos a organização do ensino de matemática, significativo para todos que o experimentam. Mais ainda, o que é possível depreender do estudo de Domite são as formas como os professores de matemática encontraram para conciliar o ensino de matemática com a proposta do trabalho pedagógico via tema gerador. Percebemos, portanto, e isso gostaríamos de enfatizar, as formas como a estruturação da política curricular proposta pela Secretaria é recontextualizada pelos professores, conforme defende Lopes (2005), revelando caminhos possíveis de aproximação entre aquilo que desejavam Freire e sua equipe e o cotidiano das salas de aula da rede municipal.

A recontextualização pode ser compreendida, segundo a autora como reinterpretações, "inerentes aos processos de circulação de textos", em que se articulam "a ação de múltiplos contextos nessa reinterpretação, identificando as relações entre processos de reprodução, reinterpretação, resistência e mudança, nos mais diferentes níveis” (Lopes, 2005, p. 55). Evitando recair em uma leitura considerada estreita por tratar os processos de recontextualização como distorções ou desvios, consideramos, do mesmo modo que Lopes, que a recontextualização pode ser significativa para expressar como se dão as relações macro-micro, implicando no tratamento, por consequência do conceito de hibridismo de Stephen Ball (2001, p. 102), em que se articulam/confrontam/relacionam lógicas globais, distantes e locais. Para o autor, os discursos curriculares oficiais são confrontados com as possibilidades reais de sua realização - para além de toda a trajetória particular, de formação pessoal e profissional, dos professores -, o que faz com que possamos entender a recontextualização não como desvio, mas como possibilidade

Os autores cedem à Revista Internacional Educon os direitos de primeira publicação do presente artigo. Aplicam-se os termos de uma licença Creative Commons Atribuição 4.0 Internacional (CC BY 4.0), que permite o uso irrestrito, a distribuição e a reprodução em qualquer meio desde que a publicação original seja corretamente citada. 
de aproximação entre o que se pretende oficialmente construir e os cotidianos diversos, onde esse discurso é reinterpretado de acordo com diferentes características.

Assumir essa perspectiva implica em afirmar que, ainda que os professores e suas escolas tivessem aderido, por iniciativa própria, ao projeto de reorientação curricular e fossem acompanhados por especialistas teoricamente alinhados com a proposta, as recontextualizações e hibridismos vão necessariamente caracterizar o modo como incorporam as orientações em seus cotidianos de acordo com uma miríade de fatores. Isso fica evidente nas estratégias identificadas por Domite, uma vez que demonstram maneiras encontradas pelos professores de matemática ao tentar conciliar a formação inicial que tiveram, os objetivos do projeto, o programa de formação permanente a que estavam tendo acesso, as orientações dos especialistas e as dificuldades-potencialidades particulares de seu contexto. Nessa tentativa, emergem estratégias que não necessariamente foram previstas pela equipe de especialistas em educação matemática ou mesmo pelos gestores do movimento, mas que significam um movimento criativo no sentido de ressignificar o que aprenderam durante o movimento formativo, tendo como referência sua própria prática, seus limites e possibilidades.

\section{Considerações finais}

Compreender esse cenário, verdadeiro território em disputa como reconheceu Arroyo (2013), pode nos oferecer indícios relevantes para adicionarmos às pesquisas-políticas-práticas curriculares, especialmente inspiradas pelas perspectivas socioculturais da Educação Matemática, de modo que se consolidem como aliadas ao trabalho pedagógico. O fato de Palanch (2016, p. 125) afirmar, como resultado de sua pesquisa, que "o currículo modelado pelos professores por diversas vezes se distancia daquilo que é oficialmente prescrito" somente nos reafirma e acrescenta evidências ao argumento de que não é desejável nem sequer possível a prescrição curricular, inspirada pela ideia de que seja possível prescrever práticas homogêneas para contextos, como é o caso brasileiro, bastante diversos. Ainda que argumentem que há flexibilidade expressa na "parte diversificada" que cada município e estado pode estabelecer, as avaliações em larga-escala acabarão por pressionar um processo de estreitamento curricular, como afirmam as pesquisadoras Alicia Bonamino e Sandra Zákia Sousa (2012) ao comentar sobre os impactos das avaliações externas.

Isso nos leva também a destacar a relevância de se considerarem as práticas pedagógicas que têm sido sistematicamente invisibilizadas por tais políticas (Oliveira, 2012), fundamental quando tomamos as perspectivas socioculturais da Educação Matemática que reconhecem e acolhem o tempo dos atores nas escolas, os praticantes do currículo de matemática em seus diferentes contextos (Valle \& Santos, 20018).

A publicação dos Cadernos de Relatos de Práticas de professores/as, comentadas por especialistas, se convertia numa ferramenta interessante de formação permanente da rede municipal, que poderia aprender a identificar o que funcionou; o que não funcionou; e, principalmente, caminhos para superar o que não funcionou por meio do compartilhamento de práticas, saídas, estratégias, soluções (Valle \& Santos, 2018; Valle, 2020). Mais uma vez, se destaca a relevância e a necessidade de que esse seja um movimento acompanhado pelo olhar crítico dos/das pesquisadores/as-especialistas, o que se revela na incorporação de seus comentários aos cadernos. Ao incorporá-las, Freire e sua equipe permitem que práticas realizadas de maneira localizada, contingencial, sejam objetos de compartilhamento e estudo de toda a rede municipal, que vai se inserindo num movimento de fazerpensar currículo de maneira crítica. Evidencia-se, assim, mais um pressuposto do Movimento de Reorientação Curricular: o de superar a dicotomia entre quem pensa e quem faz currículo, tributária do que o educador considerava como educação bancária, tão presente nos paradigmas da política curricular moderna.

Concluímos, então, com a sistematização de alguns dos subsídios aprendidos da experiência da política curricular freireana, necessários para compreendermos o sentido e o significado dos princípios da pedagogia crítica de Freire mobilizados no âmbito de proposta curricular consistente e coerente: 
Revista Internacional Educon, Volume I, n. 1, e20011012, set./dez. 2020

ISSN: 2675-6722 | DOI: https:// doi.org/ 10.47764/ e20011010

Primeiro, a compreensão de que a relaşão universidade-escola tem um papel potencial e relevante na construção de políticas curriculares não-prescritivas, capazes de reconhecer e valorizar as práticas pedagógicas dos professores de matemática, praticantes legítimos do currículo, como elemento indispensável para se refletir sobre o política curricular. Durante o Movimento de Reorientação Curricular, professores e pesquisadores da Educação interagem sobre muitos interesses em comum, imersos no cotidiano das escolas, reconhecendo-se como interlocutores indispensáveis na produção de saberes, em nosso caso, da Educação Matemática;

Segundo, o entendimento de que políticas curriculares prescritivas, centralizadoras invisibilizam o trabalho pedagógico já em curso nas milhares de escolas brasileiras, além de se sustentar, via de regra, em argumentos frágeis e inconsistentes relacionados à necessidade da prescrição. A experiência freireana demonstra que tais argumentos são frágeis na medida em que estabelece uma política curricular, por adesão, na maior cidade brasileira, que reconhece e reafirma a autonomia e a autoria docente - professoras e professores reconhecidos como autores do currículo; Terceiro, a necessidade de que pesquisas em Educação Matemática se dediquem a desinvisibilizar práticas emancipatórias já em curso em aulas de matemática, tornando-as mote da relação entre universidade-escola, não sob a perspectiva de que a universidade deve suplantar, substituir, negligenciar os saberes-fazeres dos professores, praticantes do currículo, mas de que deve, ao invés disso, contribuir com aquilo que já se faz, como a contribuição dos especialistas no Caderno de Relatos de Práticas, visando seu aperfeiçoamento, que não se dá deslocado do contexto e do cotidiano onde se pratica o currículo;

Quarto, também a necessidade de sistematizar e tornar públicas - acessíveis aos professores da Educação Básica, em especial das escolas públicas brasileiras - as contribuições da Etnomatemática, da Educação Matemática Crítica, da Modelagem e de outras vertentes da Educação Matemática para a prática pedagógica.

Tais pontos evidentemente não esgotam o debate e a reflexão sobre as práticas-políticaspesquisas sobre currículos e currículos de matemática. Pretendemos com eles, ao invés disso, argumentar em favor de outras possibilidades de compreensão curricular, capazes de tornar a política permeável ao trabalho que se realiza no "chão da escola" por professoras e professores de matemática comprometidos com uma educação não-tecnicista, crítica, emancipatória e democrática.

\section{Referências}

ANPEd, Associação Nacional de Pós-graduação e Pesquisa em Educação. ABDC, Associação Brasileira de Currículo. (2015) Ofício no 01/2015 - GR: Exposição de motivos sobre a Base Nacional Comum Curricular.

de:http://www.anped.org.br/sites/default/files/resources/Of_cio_01_2015_CNE_BNCC.pdf

Recuperado

Arroyo, M. (2013). Currículo, território em disputa. Petrópolis: Vozes.

Ball, S. (2001). Diretrizes políticas globais e relações políticas locais em educação. Currículos sem Fronteiras, 1 (2), pp. 99-116.

Bauchspies, W. \& Restivo, S. (2001). O Arbítrio da Matemática: mentes, moral e números. Bolema, 14, (16), pp. 1-20.

Bigode, A. J. L. (2019). Base, que base? O caso da matemática. En: Cássio, F. \& Catelli Jr., R. (eds.). Educação é a Base? 23 educadores discutem a BNCC (pp. 123-144). São Paulo: Ação Educativa.

Os autores cedem à Revista Internacional Educon os direitos de primeira publicação do presente artigo. Aplicam-se os termos de uma licença Creative Commons Atribuição 4.0 Internacional (CC BY 4.0), que permite o uso irrestrito, a distribuição e a reprodução em qualquer meio desde que a publicação original seja corretamente citada. 
Bonamino, A. \& Sousa, S. Z. (2012). Três gerações de avaliação da educação básica no Brasil: interfaces com o currículo da/na escola. Educaşão e Pesquisa, 38 (2), pp. 373-388.

Brasil. (1997). Parâmetros curriculares nacionais: matemática/Secretaria de Educação Fundamental. - Brasília: $\mathrm{MEC} / \mathrm{SEF}$.

Brasil. (2004). Diretrizes Curriculares Nacionais para a Educação das Relações Étnico-Raciais e para o Ensino de História e Cultura Afro-Brasileira e Africana — Brasília: Ministério da Educação.

Brasil. (2010). Relatório de análise de propostas curriculares de ensino fundamental e ensino médio/ Maria das Mercês Ferreira Sampaio (ed.) — Brasília: Ministério da Educação/ Secretaria de Educação Básica.

Brasil. (2017). Base Nacional Comum Curricular (BNCC). Recuperado de: http://basenacionalcomum.mec.gov.br

Costa, W. N. G. \& Silva, V. L. (2010). A desconstrução das narrativas e a reconstrução do currículo: a inclusão dos saberes matemáticos dos negros e dos índios brasileiros. Educar em Revista (Impresso), 36, pp. 245-260.

Costa, W. N. G. \& Silva, V. (2016). À Sombra do Baobá: A Cultura Negra na Educação Etnomatemática. Educação em Foco, 21, pp. 685-707.

D'Ambrosio, U. (2010). From Ea, through Pythagoras, to Avatar: Different Setting for Mathematics, Mathematics in Different Settings. En: PINTO, M. M. F.; KAWASAKI, T.F. (eds.) Proceedings of the 34th Conference of the International Group for the Psychology of Mathematics Education/PME, Belo Horizonte, 1, pp. 120.

D’Ambrosio, U. (2020). Ethnomathematics: past and future. Revemop, 2, pp. 1-14.

D’Ambrosio, U. \& Domite, M. C. S. (1997). A conversation with Paulo Freire. For the Learning of Mathematics, 17 (3), pp. 7-10.

Domite, M. C. S. (1993). Problematização: um caminho a ser percorrido em educação matemática. (Tesis doctoral). Universidade Estadual de Campinas, Campinas.

Dourado, L. F. \& Aguiar, M. A. (eds.). (2018). A BNCC na contramão do PNE 2014-2024: avaliação e perspectivas. Recife: ANPAE.

Ernest, P. (1991). The philosophy of mathematics education. Abingdon: Routledge Falmer.

Gomes, N. L. (2017). O movimento negro educador: saberes construídos nas lutas por emancipação. Petrópolis: Vozes.

Lopes, A. C. (2005). Política de currículo: recontextualização e hibridismo. Currículo sem fronteiras, 5 (2), pp. 50-64.

Lopes, A. C. \& Macedo, E. (2011). Teorias de currículo. São Paulo: Cortez. 
Oliveira, E. C. (2002). Currículo recomendado, ensinado e aprendido: o currículo de Matemática da Rede Municipal de Ensino de São Paulo. São Paulo: Arte \& Ciência.

Oliveira, I. B. (2012). O currículo como criação cotidiana. Petrópolis: DP et Alii.

Palanch, W. B. L. (2016). Mapeamento de pesquisas sobre curriculos de Matemática na Educaşão Básica brasileira (1987 a 2012). (Tesis doctoral). Pontifícia Universidade Católica de São Paulo, São Paulo.

Pires, C. M. C. (2008). Educação Matemática e sua Influência no Processo de Organização e Desenvolvimento Curricular no Brasil. Bolema, 21 (29), pp. 13-42.

Pires, C. M. C. \& Silva, M. A. (2011). Desenvolvimento curricular em Matemática no Brasil: trajetórias e desafios. Quadrante, XX (2), pp. 57-81.

Prefeitura Municipal de São Paulo (PMSP/SME). (1992). O Movimento de Reorientaşão Curricular na Secretaria Municipal de Educação de São Paulo: Documento 5 - Visão de área (Matemática). São Paulo: SME.

Sachs, L. (2018). Currículo de matemática na educação do campo: panoramas e zoons. Zetetiké, 26 (2), pp. $404-422$.

Santos, B. S. (2007). Renovar a teoria crítica e reinventar a emancipação social. São Paulo: Boitempo.

Valero, P. \& Skovsmose, O. (eds.). (2012). Educación matemática crítica. Una visión sociopolítica del aprendizaje y la enseñanza de las matemáticas. Bogotá: Una empresa docente.

Valle, J. C. A. (2020). O resgate da escola pública utópica de Freire como possibilidade inscrita na história: o movimento de reorientação curricular em São Paulo (1989-1992). REMATEC, 15 (33), pp. 201-223.

Valle J. C. A. \& Conrado, A. L. (2019). Alteridade nos currículos de matemática: a inversão do vetor e a ação dos atores na escola. TELAS, 20, pp. 106-121.

Valle, J. C. A. \& Santos, V. M. (2018). Interver o vetor do currículo: o Movimento de Reorientação Curricular de Freire em debate. Revista e-Curriculum, 16 (4), pp. 1207-1233.

\section{Sobre os Autores}

\section{JÚLIO CÉSAR AUGUSTO DO VALLE}

\section{(D) ORCID: https://orcid.org/0000-0002-7971-0405}

Professor do Instituto de Matemática e Estatística da Universidade de São Paulo (IME-USP), universidade onde se graduou em Licenciatura em Matemática, além de Mestre (2015) e Doutor (2019) em Educação. É especialista em Políticas Públicas para a Igualdade Social na América Latina pelo Consejo Latinoamericano de Ciencias Sociales (CLACSO). Durante os dois últimos anos da graduação participou do primeiro grupo de alunos bolsistas do Programa Institucional de Bolsa de Incentivo à Docência (PIBID) na Universidade de São Paulo, campus da Capital na Escola de Aplicação. Em 2014, atuou como coautor do caderno de Grandezas e Medidas do Pacto Nacional pela Alfabetização na Idade Certa (PNAIC) do Ministério da Educação (MEC). É membro do Grupo de Estudos e Pesquisas em

Os autores cedem à Revista Internacional Educon os direitos de primeira publicação do presente artigo. Aplicam-se os termos de uma licença Creative Commons Atribuição 4.0 Internacional (CC BY 4.0), que permite o uso irrestrito, a distribuição e a reprodução em qualquer meio desde que a publicação original seja corretamente citada. 
Etnomatemática (GEPEm) desde 2012, da Faculdade de Educação da Universidade de São Paulo. Em Janeiro de 2017, aceitou o convite para se tornar Secretário de Educação e Cultura de Pindamonhangaba, tornando-se, em 2019, Secretário Municipal de Educação, após a reorganização administrativa das áreas, cargo que exerceu até Março de 2020.

Enviado em: 5 ago. 2020

Aceito em: 21 set. 2020. 